\title{
Therapeutic inhibition of SGK1 suppresses colorectal cancer
}

\author{
Xuchun Liang ${ }^{1,6}$, Chunling Lan ${ }^{2,6}$, Guanming Jiao ${ }^{1,6}$, Wencheng $\mathrm{Fu}^{1}$, Xuesha Long ${ }^{1}$, Yu An ${ }^{2}$, Kejin Wang ${ }^{1}$,
} Jinzhe Zhou ${ }^{3}$, Ting Chen ${ }^{4}$, Yongqin $\mathrm{Li}^{1}$, Jiahong $\mathrm{Xu}^{5}$, Qi Huang ${ }^{3}$, Bin $\mathrm{Xu}^{2}$ and Junjie Xiao ${ }^{1}$

Colorectal cancer (CRC) is one of the leading causes of death worldwide. Thus, the development of new therapeutic targets for CRC treatment is urgently needed. SGK1 is involved in various cellular activities, and its dysregulation can result in multiple cancers. However, little is known about its roles and associated molecular mechanisms in CRC. In present study, we found that SGK1 was highly expressed in tumor tissues compared with peri-tumor samples from CRC patients. In vitro experiments revealed that SGK1 overexpression promoted colonic tumor cell proliferation and migration and inhibited cell apoptosis induced by 5-fluorouracil (5-FU), while SGK1 shRNA and inhibitors showed the inverse effects. Using CRC xenograft mice models, we demonstrated that knockdown or therapeutic inhibition of SGK1 repressed tumor cell proliferation and tumor growth. Moreover, SGK1 inhibitors increased p27 expression and promoted p27 nuclear accumulation in colorectal cancer cells, and p27 siRNAs could attenuate the repression of CRC cell proliferation induced by SGK1 inhibitors. Collectively, SGK1 promotes colorectal cancer development via regulation of CRC cell proliferation, migration and survival. Inhibition of SGK1 represents a novel strategy for the treatment of CRC.

Experimental \& Molecular Medicine (2017) 49, e399; doi:10.1038/emm.2017.184; published online 24 November 2017

\section{INTRODUCTION}

Colorectal cancer (CRC) is one of the most common malignancies diagnosed in both males and females. ${ }^{1}$ At present, surgical resection of the tumor and adjuvant treatment with chemotherapeutic agents remain the primary choice for treatment. However, $45 \%$ of patients still die after surgery because of distinct metastases. ${ }^{2}$ EGFR-specific monoclonal antibodies, such as cetuximab and panitumumab, and EGFR signaling pathway inhibitors are the most effective and widely used drugs for the treatment of CRC patients. ${ }^{3,4}$ Nevertheless, anti-EGFR treatments are ineffective for a substantial proportion of CRC patients, indicating the heterogeneity of colonic tumors and the urgent need to develop new drug targets for CRC. ${ }^{5}$

Serum- and glucocorticoid-inducible kinase 1 (SGK1) was originally isolated from a screen for transcripts induced by glucocorticoids and serum in a mammary tumor cell line. ${ }^{6}$ There are two closely related paralogs, SGK2 and SGK3, which share $80 \%$ amino-acid identity with SGK1 in their catalytic domains. ${ }^{7}$ SGK1 has been shown to be regulated by multiple factors, including the tumor suppressor protein p53, growth factors and various cellular stressors, such as DNA damage, cell shrinkage and oxidative stress. ${ }^{8-12}$ As a member of the AGC kinase family, SGK1 phosphorylates a variety of proteins, including core components of signal pathways that play important roles in multiple cellular processes, such as cell growth, proliferation, survival and apoptosis. Proteins that promote cell growth and inhibit apoptosis are frequently involved in cancer development. ${ }^{13}$ Significant upregulation of SGK1 was reported in several tumors. ${ }^{14}$ SGK1 promoted cell growth of prostate cancer cell lines ${ }^{15}$ and presumably mediated cell survival in cholangiocarcinoma and kidney cancer cells. ${ }^{16-18}$ In addition, SGK1 promotes cancer cell proliferation through multiple pathways, including the forkhead transcription factor Foxo3a/FKRHL1, c-fms, p27 and NF-KB. ${ }^{19-22}$

\footnotetext{
${ }^{1}$ Regeneration and Ageing Lab, School of Life Science, Shanghai University, Shanghai, China; ${ }^{2}$ Department of Chemistry, Qianweichang College, Innovative Drug Research Center, Shanghai University, Shanghai, China; ${ }^{3}$ Department of General Surgery, Tongji Hospital, Tongji University School of Medicine, Shanghai, China; ${ }^{4}$ Department of Dermatology, First Affiliated Hospital, Wenzhou Medical University, Wenzhou, China and ${ }^{5}$ Department of Cardiology, Tongji Hospital, Tongii University School of Medicine, Shanghai, China

${ }^{6}$ These authors contributed equally to this work.

Correspondence: Dr J Xiao, Regeneration and Ageing Laboratory, School of Life Science, Shanghai University, 333 Nan Chen Road, Shanghai 200444 , China.

E-mail: junjiexiao@shu.edu.cn

or Dr B Xu, Department of Chemistry, Qianweichang College, Innovative Drug Research Center, Shanghai University, 99 Shang Da Road, Shanghai 200444 , China.

E-mail: xubin@shu.edu.cn

Received 5 February 2017; revised 7 May 2017; accepted 23 May 2017
} 
Moreover, SGK1 interferes with the signaling of membrane androgen receptors, which stimulate apoptosis of prostate tumor cells and protect against tumor growth. ${ }^{23}$ Although previous studies have reported that intestinal tumor growth depended on SGK1 expression in APC-deficient mice, ${ }^{24}$ and a SGK1 inhibitor promoted radiation-induced suicidal death of colon tumor cells, ${ }^{25}$ the cellular role and molecular mechanisms of SGK1 in colorectal cancer in vitro and in vivo have not yet been elucidated.

P27, a cyclin-dependent kinase inhibitor, suppresses cell proliferation by regulating G1/S-phase transition. ${ }^{26,27}$ As a tumor suppressor, p27 is mislocalized, and its expression levels are reduced in most human cancers, although p27 is rarely mutated or deleted in cancers. ${ }^{28}$ Regulation of p 27 activity by SGK1 has been investigated in human melanoma cell lines. ${ }^{22}$ However, their relationship with colorectal cancer pathogenesis is not clear. Here we provide direct evidence that SGK1 plays vital roles in the development of CRC in vitro and in vivo. The present study also demonstrated that SGK1 promotes colonic tumor cell proliferation and migration and inhibits 5-fluorouracil (5-FU)induced colonic tumor cell apoptosis. We also showed that the decreased expression and increased nuclear accumulation of p27 are responsible for SGK1-induced CRC cell proliferation. Importantly, therapeutic inhibition of SGK1 suppressed colorectal cancer development, indicating that inhibition of SGK1 might be a novel strategy for the treatment of CRC.

\section{MATERIALS AND METHODS}

\section{Patients and clinical specimens}

Fifty-nine patients with histologically confirmed colorectal adenocarcinoma who had undergone surgery at Shanghai Tongji Hospital were recruited in this study. Ethical approval for the tissue collection protocol was obtained from the research ethics committee of Shanghai Tongji Hospital. Written approval consent forms were obtained from all patients before surgery. Peri-tumor and tumor samples were obtained, snap-frozen at liquid nitrogen and stored at $-80{ }^{\circ} \mathrm{C}$.

\section{Animals \\ Six-week-old immunodeficient nude mice $(\mathrm{BALB} / \mathrm{c}-\mathrm{Nu})$ were pur- chased from Cavens Laboratory Animal (Changzhou, China). These mice were maintained at $21-23^{\circ} \mathrm{C}$ and a relative humidity-controlled environment and were given feed and water ad libitum to adapt to the growth environment for 2 weeks before the experiment. All surgical procedures on animals were performed in accordance with the National Institutes of Health guidelines for the care and use of laboratory animals for biomedical research. The protocol for this study was approved by the Animal Experiments Ethics Committee of School of Life Science in Shanghai University. All surgical procedures were performed under isoflurane anesthesia, and all efforts were made to minimize animal suffering and to reduce the number of animals used.}

\section{Cell culture and transfection}

Colorectal cell lines (HCT116 and HT29) and HEK-293T cells were purchased from KeyGen Biotech (Nanjing, China). These cells were maintained in 10-cm-diameter dishes containing $10 \mathrm{ml}$ medium (HCT116 and HEK-293T cells were cultured in Dulbecco's modified Eagle's medium (DMEM), HyClone; HT29 cells were cultured in RPMI 1640 medium, KeyGen Biotech) supplemented with 10\% FBS
(Gibco, Gaithersburg, MD, USA) and 1\% penicillin-streptomycin (PS, Gibco) at $37{ }^{\circ} \mathrm{C}$ in $5 \% \mathrm{CO}_{2}$ in air at $100 \%$ humidity.

All transfections of HCT116 and HT29 cells were conducted without FBS medium in the absence of antibiotics. For functional assays, cultured cells were starved for $8 \mathrm{~h}$ and then treated with overexpression plasmids using Sinofection reagent (Sino Biological, Beijing, China) for $48 \mathrm{~h}$ or SGK1 inhibitors (GSK650394) for $24 \mathrm{~h}$. Functional rescue experiments were performed by transfecting $100 \mathrm{~nm}$ p27 siRNA into cells using Lipofectamine 2000 (Invitrogen, Carlsbad, CA, USA) for $24 \mathrm{~h}$ followed by co-incubation of $50 \mu \mathrm{M}$ (or $10 \mu \mathrm{M}$ for the rescue experiment based on EdU staining) inhibitors for an additional $24 \mathrm{~h}$. MG132 (Selleck, Houston, TX, USA), a proteasome inhibitor, was used to determine whether SGK1 regulates p27 expression via the ubiquitinproteasome-mediated system. The synthesis of siRNAs for p27 was performed by GenePharma (Shanghai, China), and the sequences are as follows: sense: 5'-ACGUAAACAGCUCGAAUUAAGTT-3', 5'-GCGC AAGUGGAAUUUCGAUUUTT- ${ }^{\prime}$, antisense: 5'-CUUAAUUCGA G CUGUUUACGUTT-3', 5'-AAAUCGAAAUUCCACUUGCGCTT-3'. The lentiviral vector-based SGK1 short hairpin RNA (shRNA) and scrambled shRNA were constructed. The sh-SGK1 was confirmed by sequencing. The sh-SGK1 sequence was cloned into the lentiviral vector pLKO.1-TRC. An empty vector or a vector carrying the SGK1 insert was co-transfected with helper plasmids (psPAX2, pMD2.G) into 293T cells to produce lentiviruses. The stable cell lines used in the construction of animal model were established by lentiviral infection supplemented with puromycin.

\section{Western blot analysis}

Nuclear and cytoplasmic proteins were extracted from HCT116 cells using nuclear and cytoplasmic protein extraction kits (KeyGen Biotech). Colorectal cancer tissues, subcutaneous tumor tissues and conditioned cells were lysed using RIPA buffer (Beyotime, Nantong, China) containing $1 \mathrm{~mm}$ PMSF (Beyotime). After determining protein concentration from a BCA standard curve by reading absorbance at $595 \mathrm{~nm}$ with a spectrophotometer, $30 \mu \mathrm{g}$ total proteins were subjected to electrophoresis and separated on a $10 \%$ SDS-PAGE and then transferred to PVDF membranes. After blocking with 5\% bovine serum albumin (BSA), antibodies against SGK1 (Abcam), P27 (Abcam, Cambridge, UK), Histone H3 (Cell Signaling Technology, West Grove, PA, USA) and GAPDH (Bioworld, Louis Park, MN, USA) were used as primary antibodies. Mouse or rabbit IgG antibodies coupled to horseradish peroxidase (HRP) were used as secondary antibodies. An enhanced electrochemiluminescence (ECL) system was used for protein band visualization.

\section{Quantitative real-time RT-PCR}

Total RNA of colorectal cancer tissues was isolated using a TRIzol RNA extraction kit (TaKaRa, Kusatsu, Japan). Then, 400 ng of RNA was subjected to reverse transcription PCR with a cDNA reverse transcription kit (TaKaRa). A SYBR-Green Supermix Kit (TaKaRa) was employed to detect mRNA levels of SGK1 and p27, and a 7900HT Fast Real-Time PCR System was used to examine the expression level of SGK1. $\beta$-actin was used as a housekeeping control for normalization. The primer sequences $\left(5^{\prime}-3^{\prime}\right)$ for SGK1, p27 and $\beta$-actin were as follows: SGK1 forward AGGATGGGTCTGAACGACTTT, reverse GCCCTTTCCGATCACTTTCAAG; p27 forward AACGTGCGAGTG TCTAACGG, reverse CCCTCTAGGGGTTTGTGATTCT; $\beta$-actin forward CATGT ACGTTGCTATCCAGGC, reverse CTCCTTAATGT CACGCACGAT. All reactions were repeated three times. Relative SGK1 and p27 expression was analyzed using the $2^{-\Delta \Delta C t}$ method. 
EdU assay

The cultured HCT116 and HT29 colorectal cells were plated in 96-well plates at a density of $2 \times 10^{5}$ cells per well after $8 \mathrm{~h}$ of serum-free starvation. Cells were treated with the inhibitor GSK650394 for $24 \mathrm{~h}$ or transfected with the overexpression plasmid or p27 siRNAs for $48 \mathrm{~h}$. Cells were exposed to 5-ethynyl-2'-deoxyuridine (EdU, RiboBio, Guangzhou, China) for $2 \mathrm{~h}$ before staining. Cells were fixed, and cell proliferation was detected with a Cell-Light EdU Cell Proliferation Detection Kit (RiboBio) following the manufacturer's protocols. The percentage of proliferative cells was observed under a fluorescent microscope (Leica Microsystems, Wetzlar, Germany). The EdUpositive ratio was calculated from 20 random fields per well.

\section{Cell cycle and apoptosis analysis by flow cytometry}

HCT116 and HT29 cells were cultured in 24-well plastic plates at a density of $2 \times 10^{5}$ cells per well, and cells treated with inhibitors, the overexpression plasmid, p27 siRNAs or 5-FU were collected. Cell cycle analysis of ethanol-immobilized HCT116 or HT29 cells was performed using propidium iodide (PI, Sigma, St Louis, MO, USA) staining followed by flow cytometry (Beckman, Miami, FL, USA). HCT116 cell apoptosis analysis was performed using Annexin V-fluorescein isothiocyanate (FITC) and PI staining according to the Annexin V-FITC Apoptosis Detection Kit (Bioworld) instructions followed by flow cytometric analysis. Cell cycle data were processed using FlowJo software (Treestar Inc., Ashland, OR, USA).

\section{Transwell assays}

SGK1 promotion of CRC migration was measured by the transwell assays performed on the HCT116 cells. Polycarbonate membranes with $8.0 \mu \mathrm{m}$ pores (Corning, New York, NY, USA) were used. HCT116 cells (400 000 cells) treated with inhibitors or overexpression plasmid were resuspended in $200 \mu \mathrm{l}$ medium without FBS and PS, and added to the upper chamber, and the bottom chamber was filled with $600 \mu \mathrm{l}$

Table 1 The clinical characteristics of the CRC patients $(n=59)$

\begin{tabular}{lc}
\hline Age $($ Mean $\pm \mathrm{SD}$, years) & $58 \pm 12$ \\
Gender & $36(61.0 \%)$ \\
Male & $23(39.0 \%)$ \\
Female & $76 \pm 8$ \\
Heart rate $(\mathrm{X} \pm \mathrm{S}$, beats per min) & $25 \pm 4$ \\
BMI $\left(\mathrm{X} \pm \mathrm{S}, \mathrm{kg} \mathrm{m}^{-2}\right)$ & \\
TNM stage & \\
I & $6(10.2 \%)$ \\
II & $26(44.1 \%)$ \\
III & $19(32.2 \%)$ \\
IV & $8(13.6 \%)$ \\
& \\
Tumor location & \\
Colon & $32(54.2 \%)$ \\
Rectum & $27(45.8 \%)$ \\
Comorbidity & \\
Hypertension & \\
Diabetes mellitus & $12(20.3 \%)$ \\
Coronary heart disease & $5(8.5 \%)$ \\
\hline
\end{tabular}

DMEM containing $10 \%$ FBS. The transwell system was incubated for $48 \mathrm{~h}$ at $37^{\circ} \mathrm{C}$, and then, the lower chamber cells that migrated through the membrane were fixed with $4 \%$ paraformaldehyde and were stained with crystal violet (Beyotime) for $5 \mathrm{~min}$. Cells that passed through the membrane were photographed using an inverted microscope.

\section{Immunohistochemistry of tissue sections}

The nude mouse tumor xenografts treated with GSK650394 or derived from SGK1-knockdown HCT116 cells were removed, fixed in paraformaldehyde and embedded in paraffin. Then, 5- $\mu$ m-thick sections were dewaxed and rehydrated using a gradient. Antigen was retrieved using high-pressure cooking, and the endogenous peroxidase activity was blocked by immersing in $0.3 \%$ hydrogen peroxide for 30 min. Then, non-specific binding was blocked with 5\% BSA, followed by incubation at $4{ }^{\circ} \mathrm{C}$ overnight with the primary antibodies anti-Ki67 (Abcam, diluted 1:300) and anti-PCNA (Abcam, diluted 1:300). Secondary antibody incubation and DAB staining were performed using an SP Immunohistochemistry Kit (KeyGen Biotech). After the cells were photographed and presented at $\times 100$ magnification with an enlarged portion at $\times 400$ magnifications with an Inverted Research Microscope (Leica), PCNA- or Ki67-positive cells were quantified to evaluate cell proliferation in the tumor region.

\section{Statistical analysis}

For statistical analysis, SPSS 20.0 and PRISM (GraphPad, La Jolla, CA, USA) software were used. Data are presented as the mean \pm s.e.m. Comparison of quantitative data was performed using an independent-samples $t$-test or one-way ANOVA test followed by Bonferroni's post hoc test. The correlation between SGK1 expression levels and TNM classification of malignant tumours (TNM) stages was analyzed by applying Pearson's correlation analysis. $P$ values $<0.05$ were considered statistically significant.

\section{RESULTS}

\section{SGK1 is upregulated in colonic tumor tissues from CRC} patients

We first compared the expression level of SGK1 in 59 pairs of tumoral and peri-tumoral samples from colorectal cancer patients. The clinical characteristics of these CRC patients used in this study were listed in Table 1. Compared with the matched peri-tumoral samples, $S g k 1$ was dramatically increased in tumoral samples as shown by qRT-PCR analysis (Figure 1a). The Sgk1 mRNA levels were not associated with TNM stage and tumor location (Figure 1b). Moreover, a significant upregulation of SGK1 in tumoral samples was also observed at the protein level (Figure 1c), indicating a potential role of SGK1 in promoting CRC development.

SGK1 promotes CRC cell proliferation and migration and inhibits the apoptosis induced by the antineoplastic agent 5-FU

To assess the effects of SGK1 on the proliferation, apoptosis and migration of CRC cells, HCT116 and HT29 cells were treated with SGK1-overexpression plasmids, SGK1 inhibitor GSK650394 or negative controls. EdU assays and flow cytometry analysis showed that forced expression of SGK1 promoted the proliferation and the G1/S-phase transition of HCT116 and HT29 cells, while treatment with the SGK1 

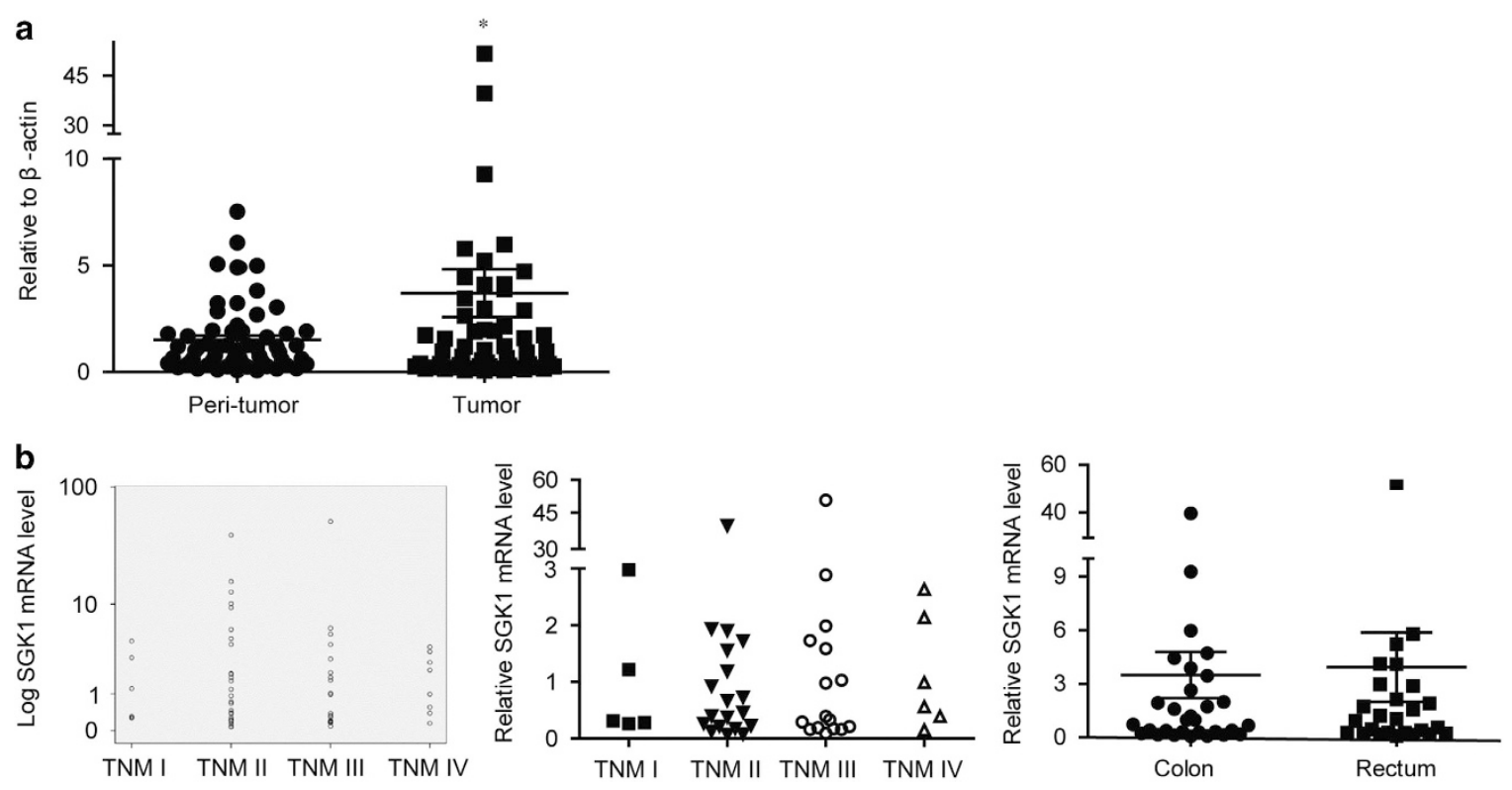

C
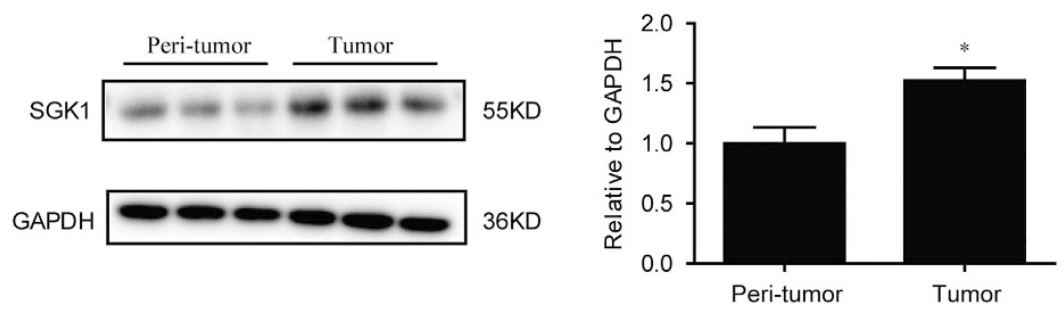

Figure 1 SGK1 is overexpressed in colonic tumor tissues from CRC patients. (a) mRNA expression of SGK1 in CRC tumor tissues compared to peri-tumor samples. (b) Correlation analysis of SGK1 mRNA levels with TNM stage and the SGK1 mRNA levels in different TNM stages and tumor samples. (c) Protein level of SGK1 in CRC tumor tissues compared to peri-tumor samples. Tissue samples for qRT-PCRs are from $59 \mathrm{CRC}$ patients and for western blot are from $3 \mathrm{CRC}$ patients. ${ }^{*} P<0.05$. CRC, colorectal cancer.

inhibitor GSK650394 showed the inverse results (Figure 2a-d). In addition, HCT116 cell apoptosis induced by the antineoplastic agent 5-FU was inhibited by SGK1 overexpression and promoted by the SGK1 inhibitor (Figure 2e). Moreover, transwell assays also showed that SGK1 overexpression promoted, while SGK1 inhibitor reduced, the migration of HCT116 cells (Figure 2f). Taken together, these in vitro results demonstrated that SGK1 promoted CRC cell proliferation and migration and inhibited 5-FU-induced apoptosis.

P27 is crucial for the role of sgk1 in CRC cell proliferation Several studies have shown that loss of p27 function promotes cancer cell progression by targeting cyclin-dependent kinases. ${ }^{29,30}$ Thus, we first evaluated the p27 level in HCT116 cells treated with the SGK1 overexpression plasmids or SGK1 inhibitor. The mRNA and protein levels of p27 were substantially decreased by the SGK1 overexpression plasmid, whereas they were enhanced by the SGK1 inhibitor, indicating the transcriptional regulation of p27 by SGK1 (Figure 3a and b). In addition to the loss of p27 expression, the subcellular localization of p27 and p27 degradation play pivotal roles in regulating cell cycle progression of tumor development. ${ }^{31}$ Thus, we investigated the p27 expression in total cell lysates, the nuclear fraction and the cytoplasmic fraction after treatment with the
SGK1 inhibitor GSK650394 and/or proteasome inhibitor MG132. The results showed that GSK650394 and MG132 could individually or jointly increase the expression of p27 in total cell lysates (Figure 3c). For subcellular p27 localization analysis, the results showed cytoplasmic loss (Figure 3d) and nuclear accumulation (Figure 3e) of p27 after GSK650394 treatment, and GSK650394 combined treatment with MG132 also resulted in nuclear accumulation of p27 in HCT116 cells. MG132 could block the ubiquitin-proteasome-mediated p27 degradation, resulting in cytoplasmic accumulation of p27 (Figure 3d). However, compared to treatment with MG132 alone, the combined treatment with GSK650394 and MG132 decreased the cytoplasmic level of p27 and increased the nuclear level of $\mathrm{p} 27$, indicating the promotion roles of SGK1 inhibitor in p27 nuclear accumulation (Figure $3 \mathrm{~d}$ and e). In addition, to elucidate whether p27 contributes to the functional roles of SGK1 in HCT116 cell proliferation, siRNAs targeting p27 were used to perform functional rescue experiments. p27 siRNAs could significantly promote HCT116 cell proliferation and the G1/S-phase transition. Notably, although it failed to completely return to the control levels, p27 siRNAs could significantly attenuate the suppressive effects of SGK1 inhibitor on the proliferation and G1-to-S-phase transition of HCT116 cells (Figure $4 \mathrm{a}$ and b). Similar results were obtained with 
a

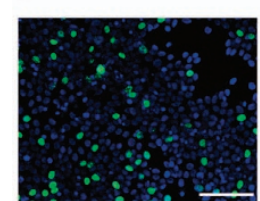

EGFP

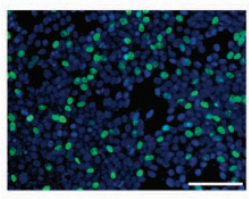

Control

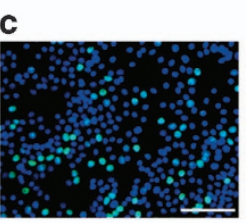

EGFP

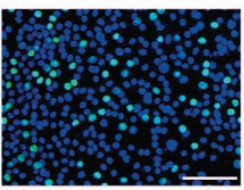

Control

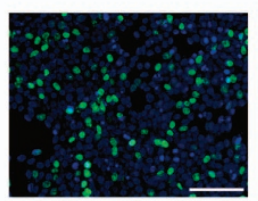

SGK1

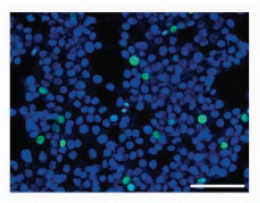

GSK650394

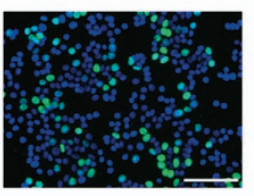

SGK1

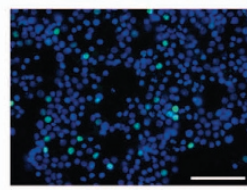

GSK650394

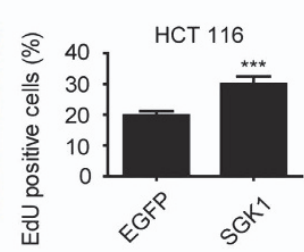

b
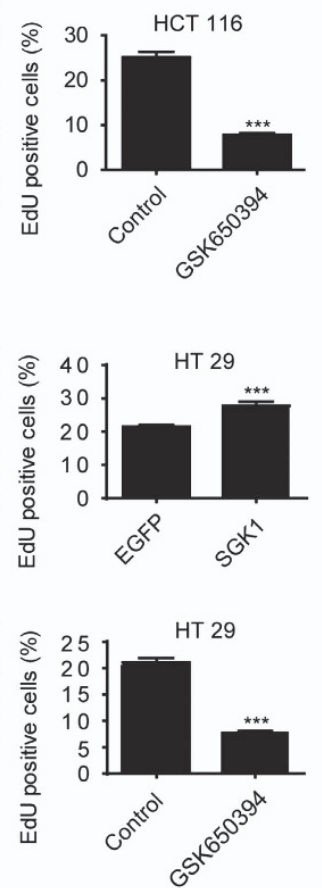

e
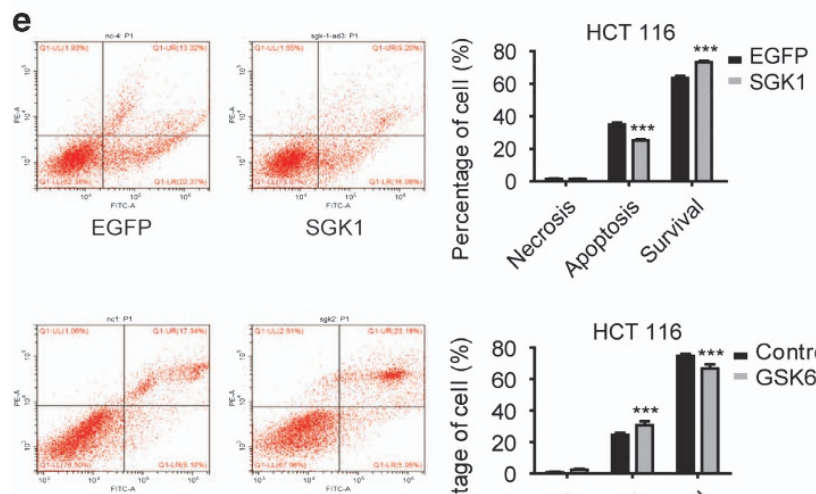

Control

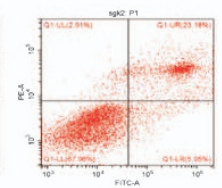

GSK650394

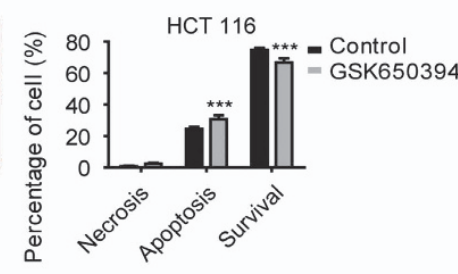

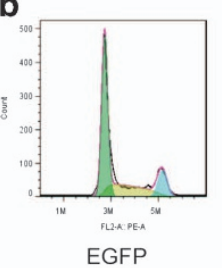

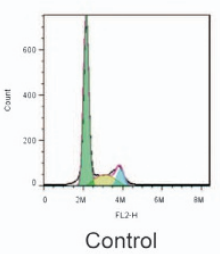

d
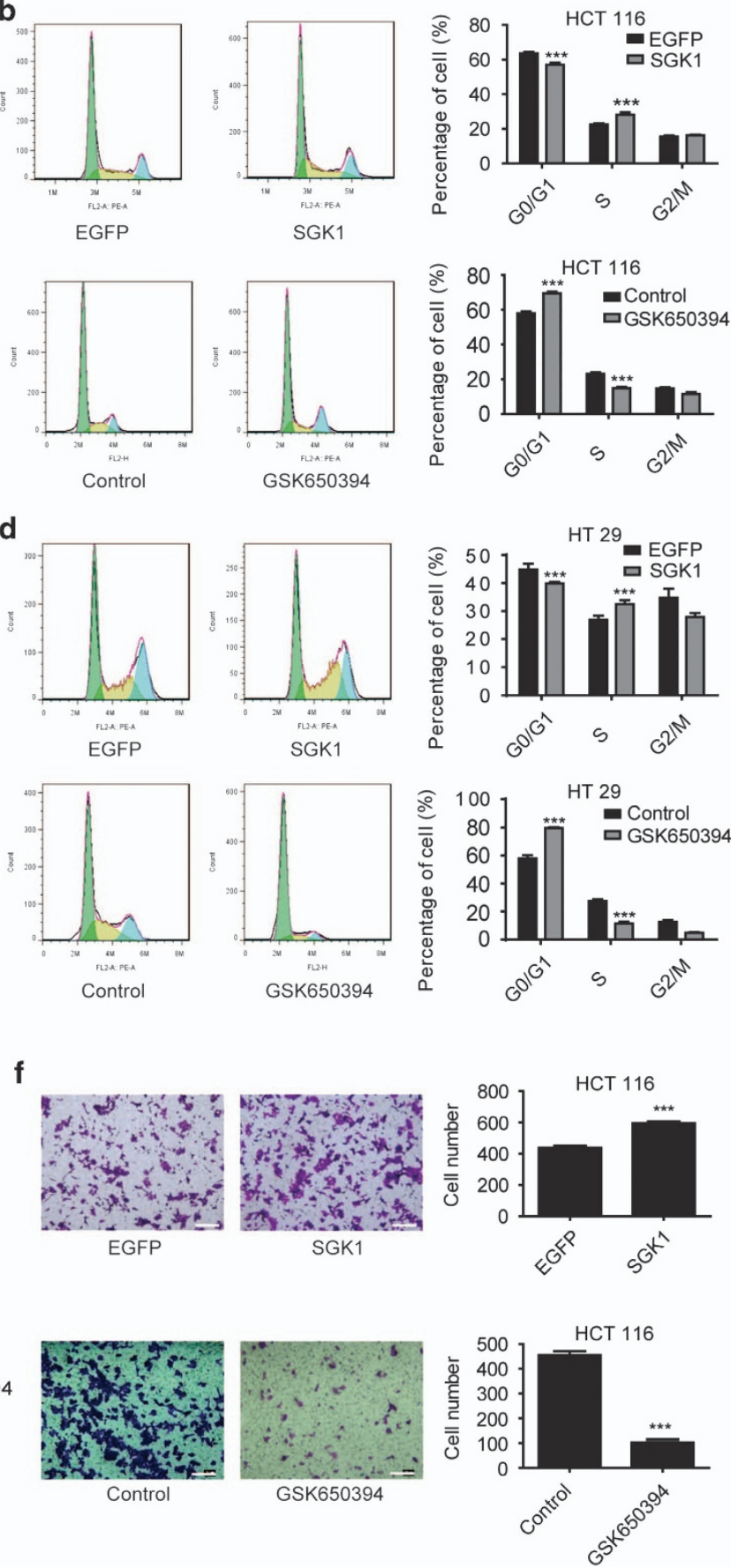

Figure 2 SGK1 promotes colonic tumor cell proliferation and migration and inhibits 5-FU-induced cell apoptosis. (a) EdU assay of HCT116 cells upon treatment with SGK1 overexpression plasmids (SGK1) and SGK1 inhibitor (GSK650394); scale bars, $200 \mu$ m; $n=4$. (b) Cell cycle analysis of HCT116 cells by flow cytometry; $n=4$. (c) EdU staining of HT29 cells; scale bars, $200 \mu$ m; $n=4$. (d) Cell cycle analysis of HT29 cells; $n=3$. (e) Cell apoptosis analysis of HCT116 cells; $n=4$. (f) Transwell analysis of HCT116 cell migration; scale bars, $100 \mu \mathrm{m} ; n=4 ;{ }^{* * *} P<0.001$.

HT29 cells (Figure 5). However, p27 siRNAs failed to rescue the effects of SGK1 inhibitor GSK650394 in 5-FU-induced apoptosis and migration of HCT116 cells (Supplementary Figures S1 and 2). Collectively, these results indicate that SGK1 inhibitors repress colorectal cancer proliferation, at least in part via p27 increase and nuclear accumulation.
The SGK1 is essential for CRC tumor growth and cell proliferation in the subcutaneous xenotransplant mouse model

The above results provide in vitro evidence that SGK1 promotes CRC development. Next, we investigated the function of SGK1 in CRC tumor development using an in vivo 


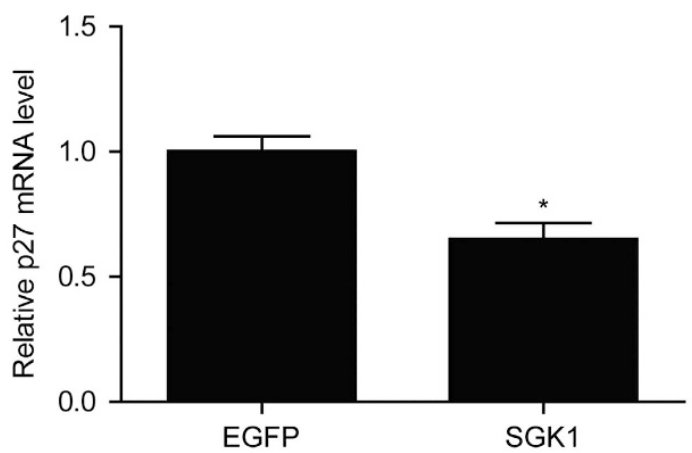

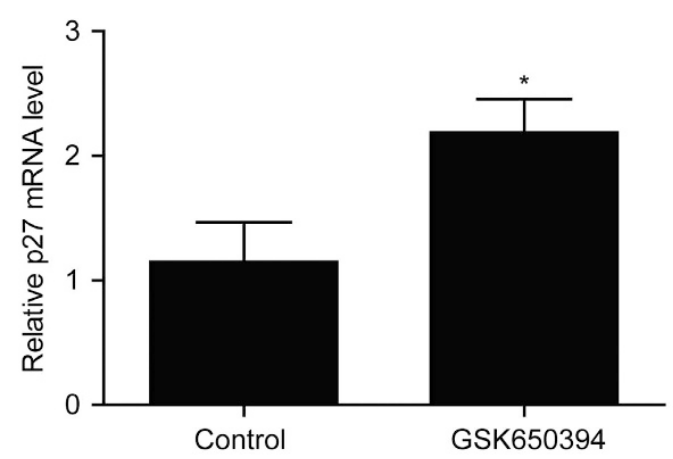

b

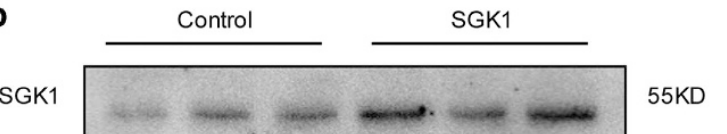

p27

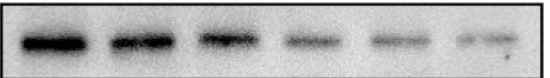

$27 \mathrm{KD}$

GAPDH

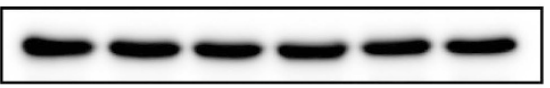

$36 \mathrm{KD}$
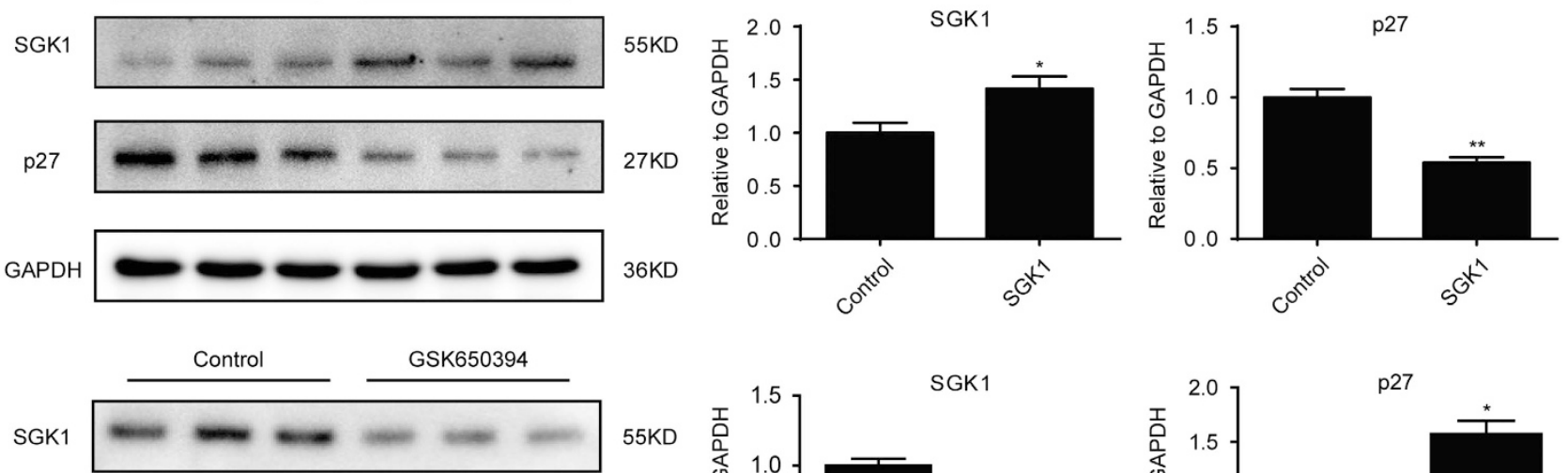

p27
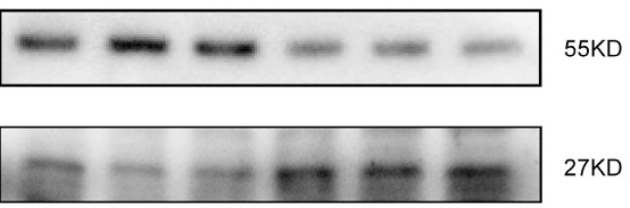

GAPDH

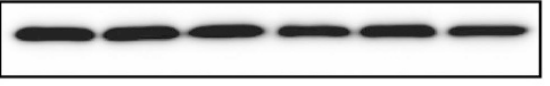

36KD
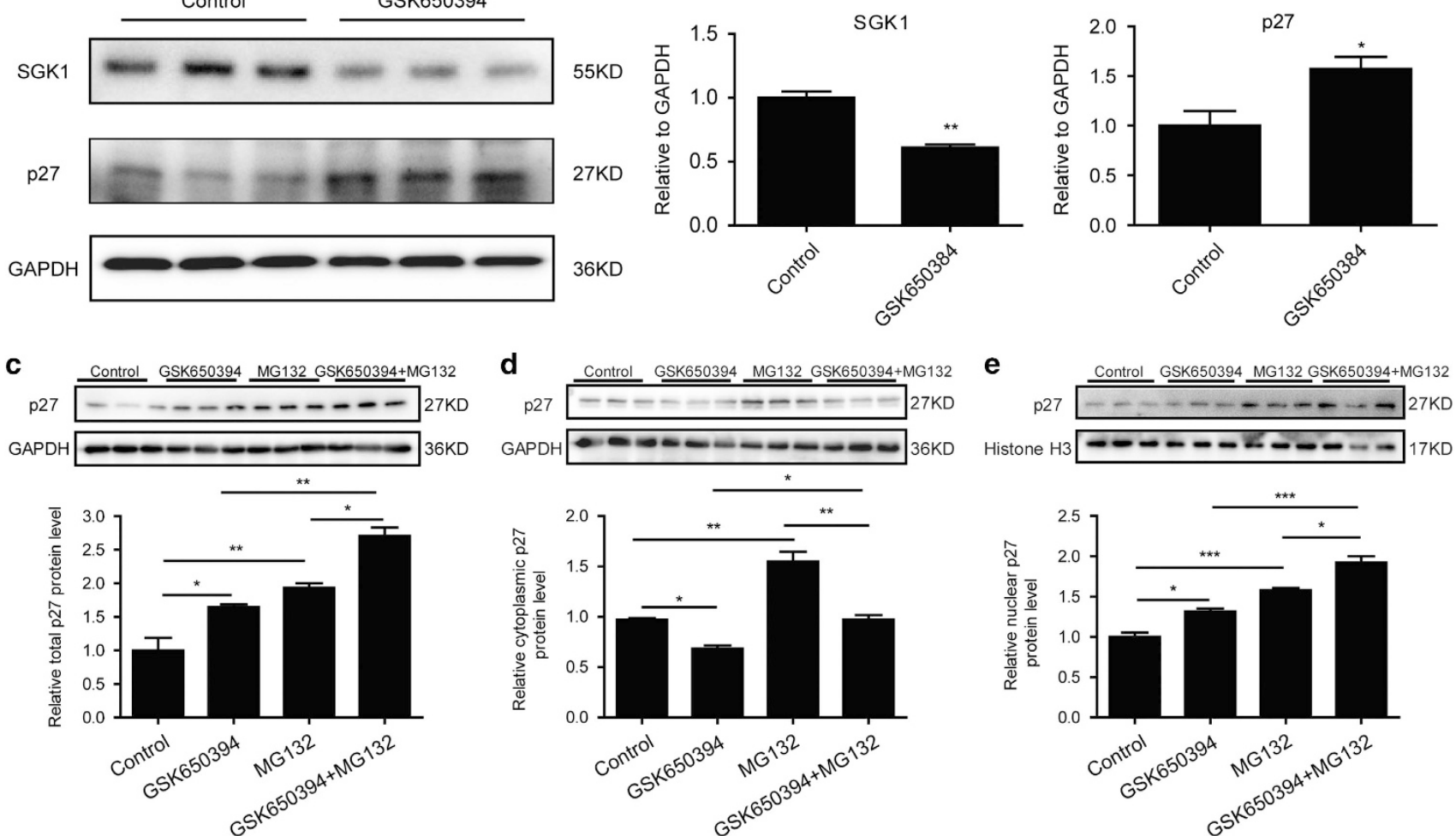

Figure 3 SGK1 regulates p27 mRNA and protein levels. (a) p27 mRNA levels in HCT116 cells treated with SGK1 overexpression plasmids or the SGK1 inhibitor GSK650394. (b) p27 and SGK1 protein expression levels. (c-e) HCT116 cells treated with GSK650394 (10 $\mu \mathrm{m}$ ), MG132 $(10 \mu \mathrm{m})$ or GSK650394 $(10 \mu \mathrm{M})+$ MG132 $(10 \mu \mathrm{M})$ for $24 \mathrm{~h}$ were subjected to western blot analysis to detect p27 in total cell lysates (c), the cytoplasmic fraction (d) and the nuclear fraction (e). ${ }^{*}, 0.01<P<0.05 ;{ }^{* *}, 0.001<P<0.01 ;{ }^{* * *} P<0.001$.

subcutaneous xenotransplant mouse model. We first established the lentivirus-based SGK1 shRNA stable expression HCT116 cell line. As confirmed by western blot, SGK1 was efficiently reduced in HCT116 cells that were stably transfected with SGK1 shRNA (Figure 6a). Eight-week-old nude mice were subcutaneously implanted with HCT116-SGK1-shRNA stable cell line on day 0 , and the tumor volume was calculated every 4 days until the mice were killed on day 28 (Figure 6b). In the xenograft CRC tumors harvested on day 28 , tumors generated from SGK1 shRNA-stable-expression cell line displayed 
a
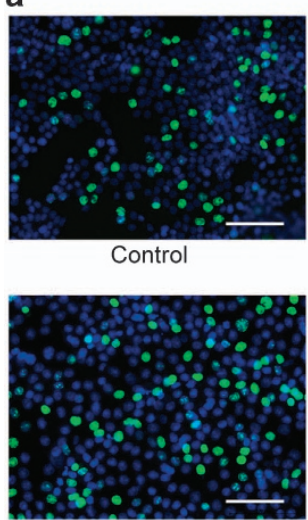

p27-siRNA2

b
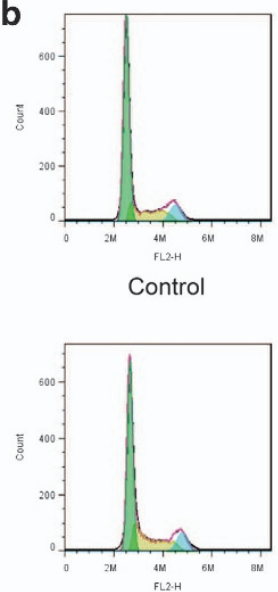

p27-siRNA2

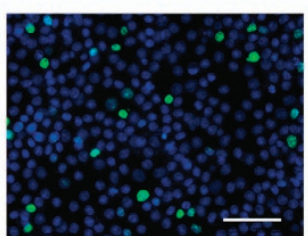

GSK650394

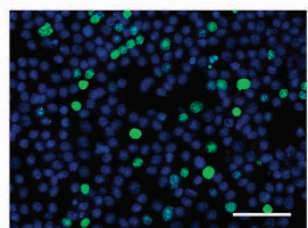

GSK650394

+p27-siRNA1

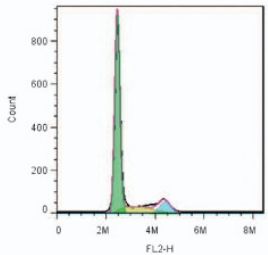

GSK650394

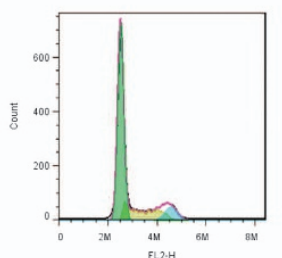

GSK650394

+p27-siRNA1

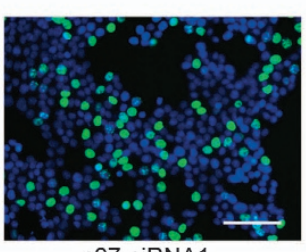

p27-siRNA1
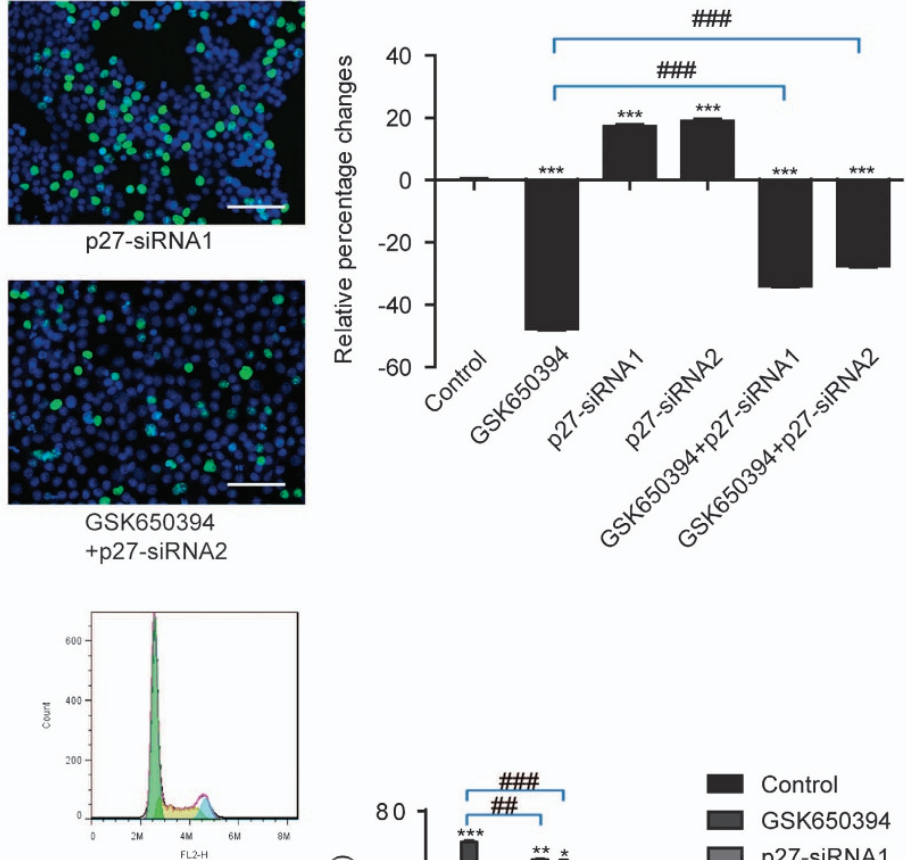

p27-siRNA1

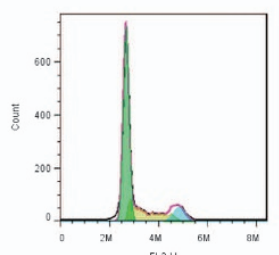

GSK650394

+p27-siRNA2

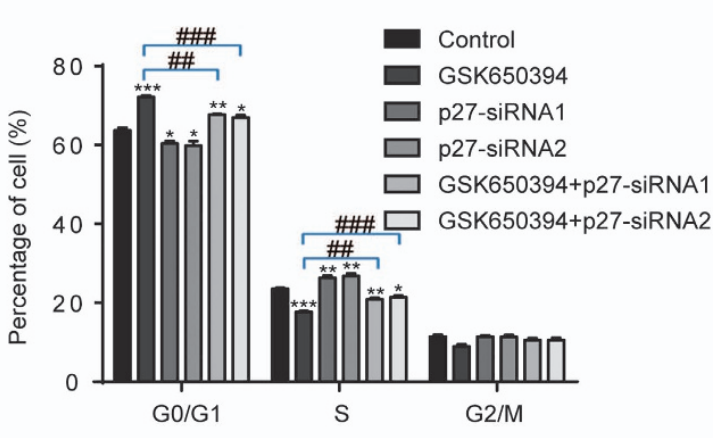

Figure 4 p27 is involved in the SGK1 signaling pathway for the regulation of HCT116 cell proliferation. (a) Relative percentage changes of the proportion of EdU-positive cells compared to control; scale bars, $200 \mu \mathrm{m} ; n=4$. (b) HCT116 cell cycle analysis; $n=4$. * and ${ }^{\#}$, $0.01<P<0.05 ;{ }^{* *}$ and ${ }^{\# \#}, 0.001<P<0.01 ; * *$ and ${ }^{\# \# \# P<0.001 .}$

decreased SGK1 expression and increased p27 expression (Figure 6c), indicating that SGK1 could also repress p27 in vivo. In addition, SGK1 knockdown markedly reduced the tumor growth of implanted colorectal cancer as shown by the decreased tumor volume and size (Figure $6 \mathrm{~d}$ and e). Furthermore, immunohistochemical staining of Ki67 and PCNA showed that knockdown of SGK1 impeded cell proliferation in xenograft CRC tumors (Figure 6f). Therefore, these results clearly demonstrate that SGK1 is essential for CRC tumor growth and cell proliferation in vivo.

Therapeutic SGK1 inhibition represses tumor growth and proliferation of implanted CRC tumor cells

To further explore the therapeutic effect of SGK1 inhibition on CRC, we established the xenotransplant model through injecting subcutaneously with HCT116 cells to nude mice, followed by treatment with the SGK1 inhibitor GSK650394 (Figure 7a). Mice injected with GSK650394 showed reduced SGK1 expression and increased p27 expression levels in xenograft CRC tissues on day 22 (Figure 7b). Importantly, the SGK1 inhibitor markedly reduced the xenograft tumor volume and decreased the tumor size (Figure $7 \mathrm{c}$ and $\mathrm{d}$ ). Immunohistochemical analysis of proliferation markers showed a significant reduction in the Ki67- and PCNA-positive cell populations in xenograft tumors treated with SGK1 inhibitors (Figure 7e). Taken together, these data suggest that therapeutic SGK1 inhibition is sufficient to impede tumor development of implanted colorectal cancer in vivo.

\section{DISCUSSION}

SGK1 is involved in cell proliferation, migration, invasion and apoptosis, indicating its critical roles in cancer development. Although SGK1 has been reported to be essential for several cancers, the molecular mechanisms of SGK1 in CRC are unclear. We first showed that SGK1 was highly expressed in colonic tumor samples from CRC patients, and it was essential for CRC development via the promotion of tumor cell proliferation, migration and survival. We also 

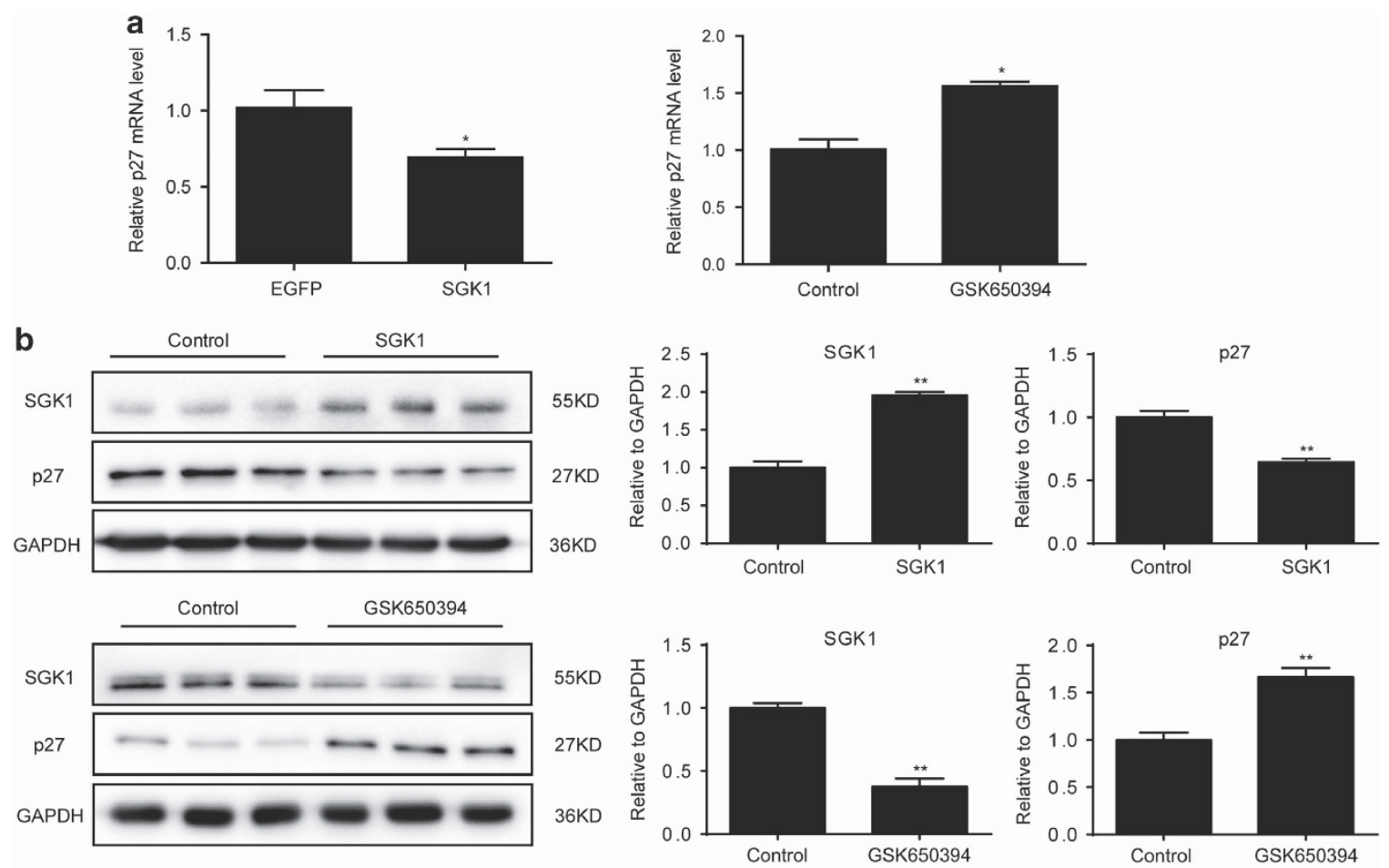

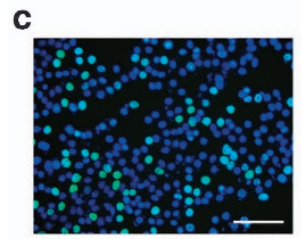

Control

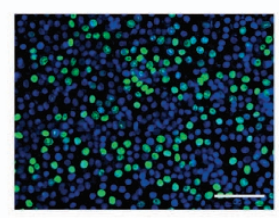

p27-siRNA2

d
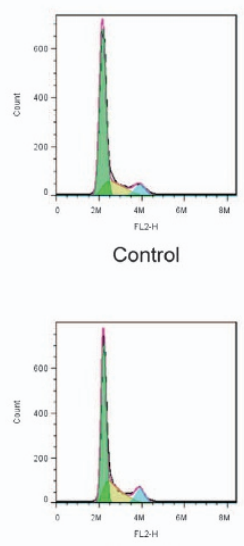

p27-siRNA2

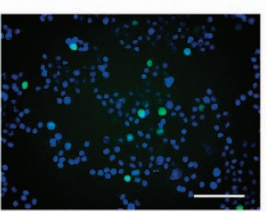

GSK650394

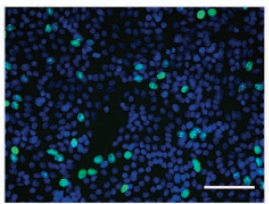

GSK650394

+p27-siRNA1

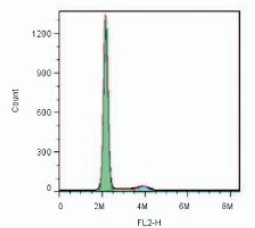

GSK650394

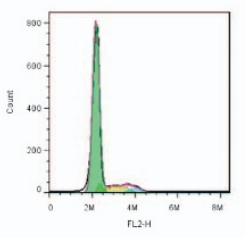

GSK650394 +p27-siRNA

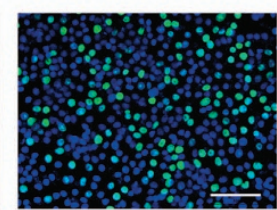

p27-siRNA1

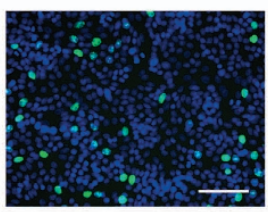

GSK650394

+p27-siRNA2

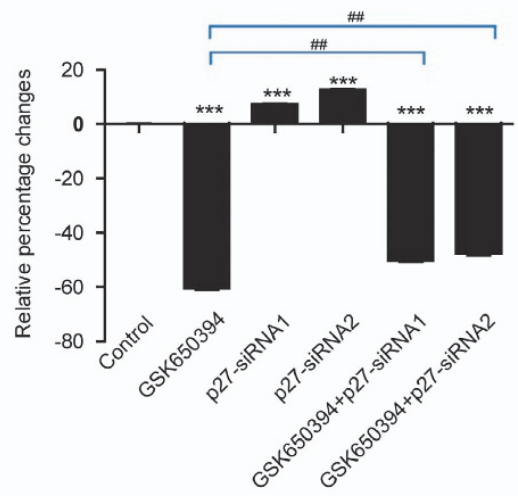

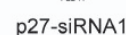
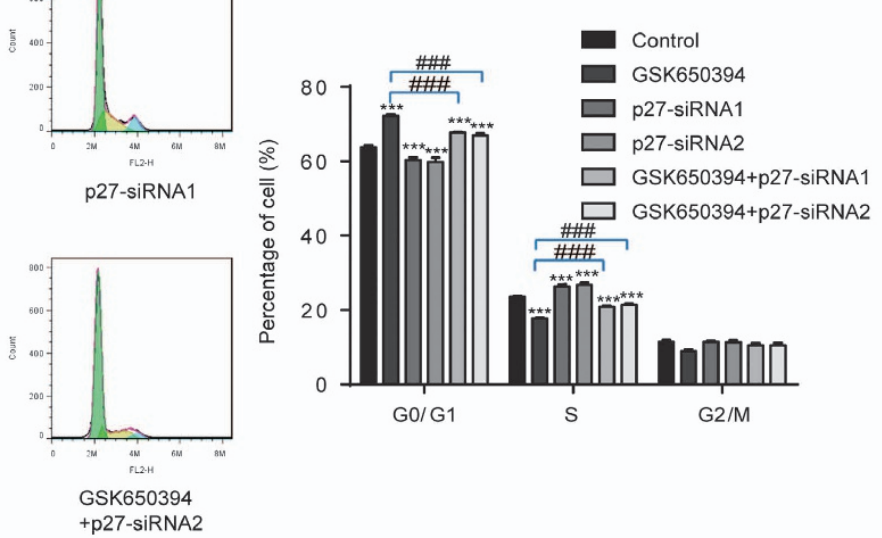

+p27-siRNA2

Figure 5 p27 is involved in the SGK1 signaling pathway for the regulation of HT29 cell proliferation. (a) p27 mRNA levels in HT29 cells treated with SGK1 overexpression plasmids or SGK1 inhibitor GSK650394; (b) P27 and SGK1 protein expression levels. (c) Relative percentage changes of the proportion of EdU-positive cells compared to control; scale bars, $200 \mu \mathrm{m} ; n=4$. (d) HT29 cell cycle analysis; $n=4$. ${ }^{\#}, 0.01<P<0.05 ; * *, 0.001<P<0.01 ; * * *$ and ${ }^{\# \# \#, P<0.001 .}$ 
a

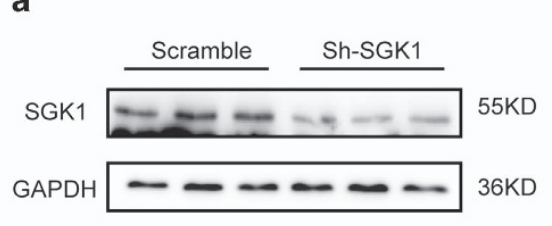

C

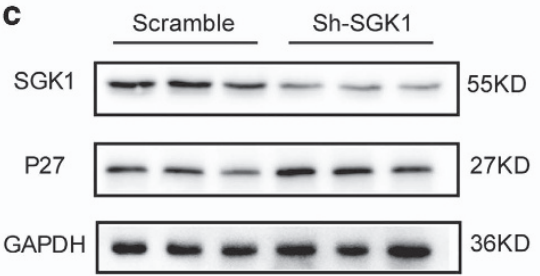

d

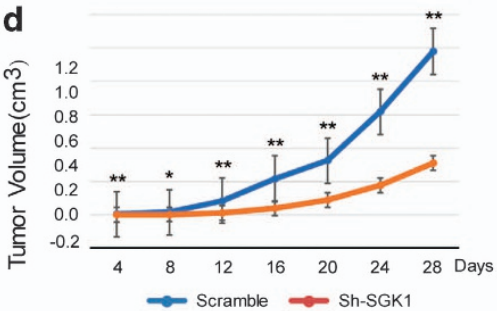

f
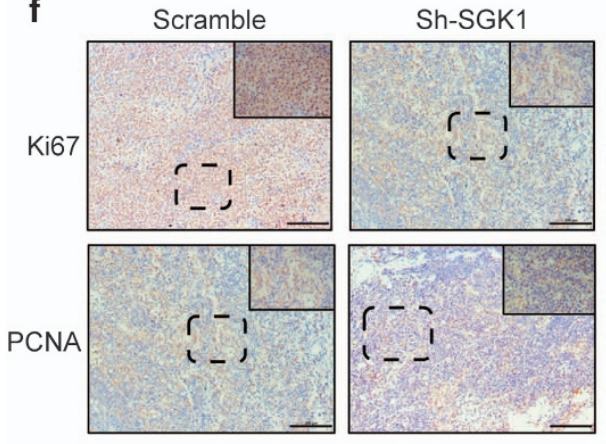

Sh-SGK1

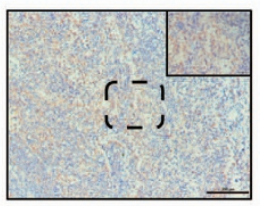

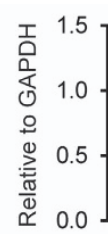

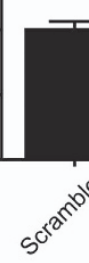

b

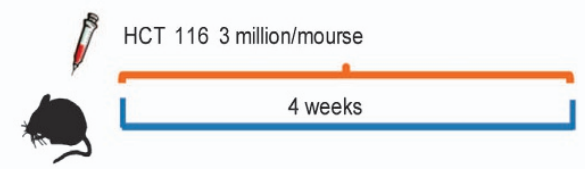

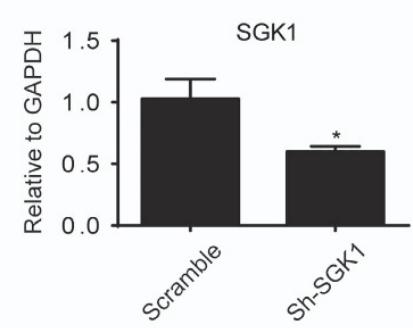

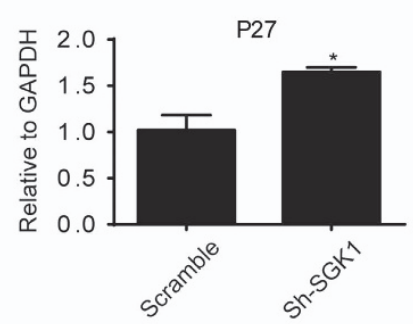

e
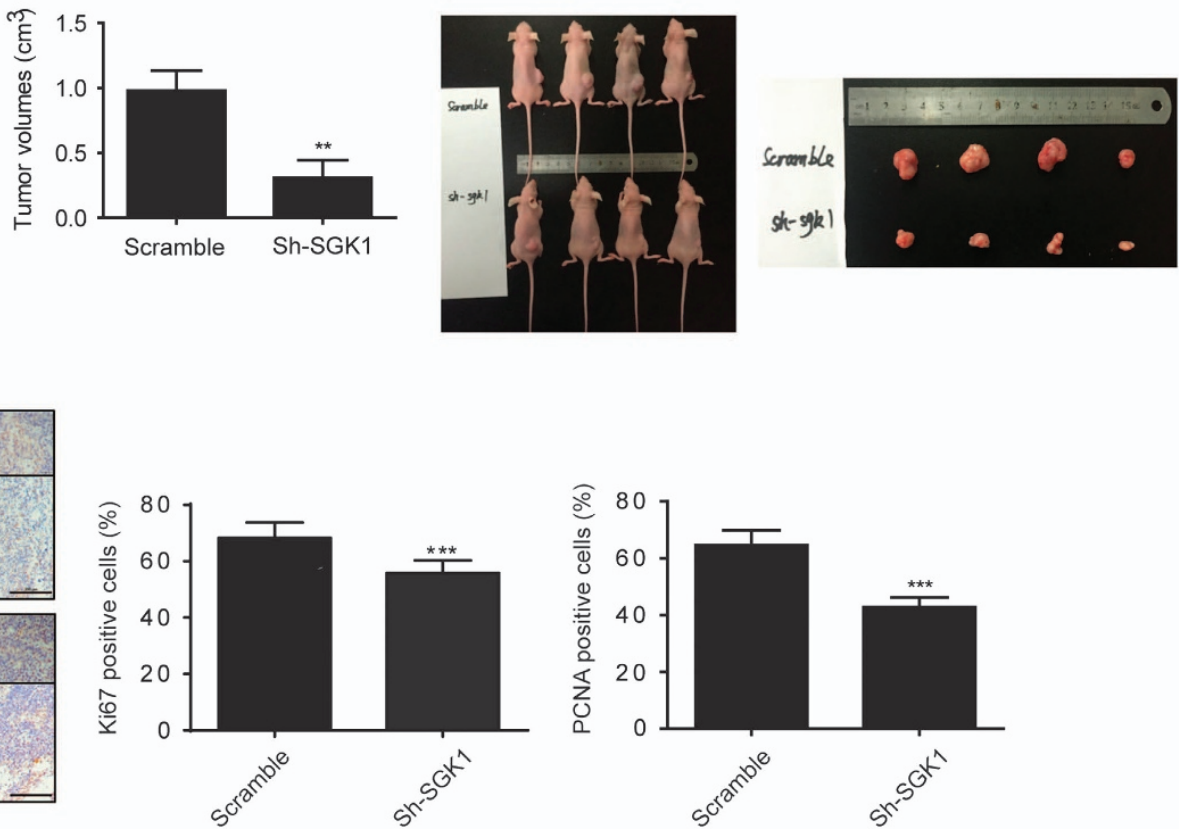

Figure 6 SGK1 shRNA upregulates p27 expression and attenuates tumor growth and cellular proliferation in the subcutaneous xenograft mouse model. (a) Establishment of the lentivirus-based SGK1 shRNA stable HCT116 cell line. (b) Establishment of the xenotransplant mouse model; $n=4$. (c) p27 expression in xenograft tumor samples. (d, e) Transplanted tumor volume and size; $n=4$. (f) Ki67- and PCNA-positive cell populations in xenograft tumor tissues. Scale bars, $200 \mu \mathrm{m} ;{ }^{*} P<0.05 ;{ }^{*} P<0.01 ;{ }^{* * *} P<0.001$.

demonstrated that SGK1 inhibition reduced CRC tumor growth and cell proliferation in mice. Importantly, the present study identified p27 as a pivotal downstream factor contributing to CRC development and cell proliferation promoted by SGK1.

SGK1 has been shown to promote cell growth and proliferation in several cancer cells, such as prostate, human melanoma and kidney cancer cells. ${ }^{15,16,22}$ SGK1 has also been identified as a downstream factor of the PI3Kinase pathway and interacts with GSK3 and various factors of the RAS/RAF/ ERK pathway, which promote cell growth and proliferative signals in both normal and malignant cellular functions. ${ }^{9,32-34}$
In addition to cell growth and proliferation, cell survival and migration are also crucial for the development of cancers. ${ }^{13}$ Our data demonstrated that SGK1 overexpression promoted CRC cell proliferation, migration and cell survival, whereas the SGK1 inhibitor and shRNA had the inverse effects. Moreover, in a CRC xenograft murine model, SGK1 shRNA decreased the xenograft tumor growth, suggesting that SGK1 is necessary for the development of CRC. Importantly, the SGK1 inhibitor also reduced the tumor growth and cellular proliferation in CRC xenograft models, suggesting that therapeutic inhibition of SGK1 is sufficient to prevent colonic tumor development in vivo. 
a

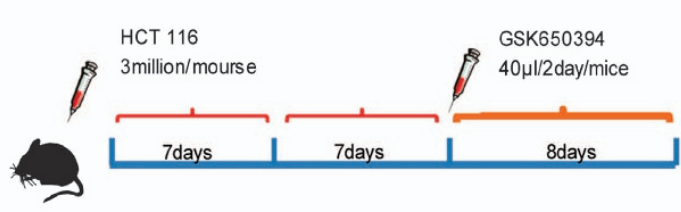

b

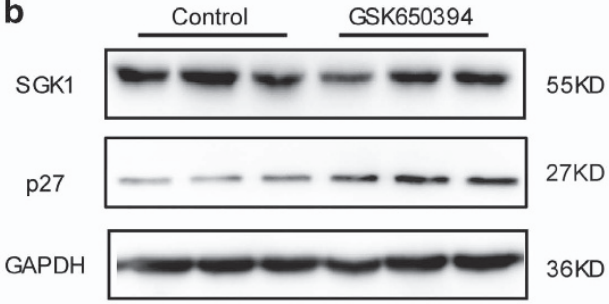

C
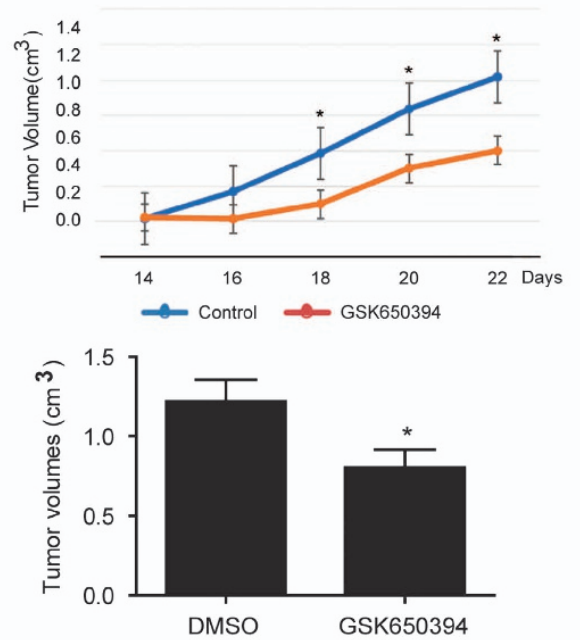
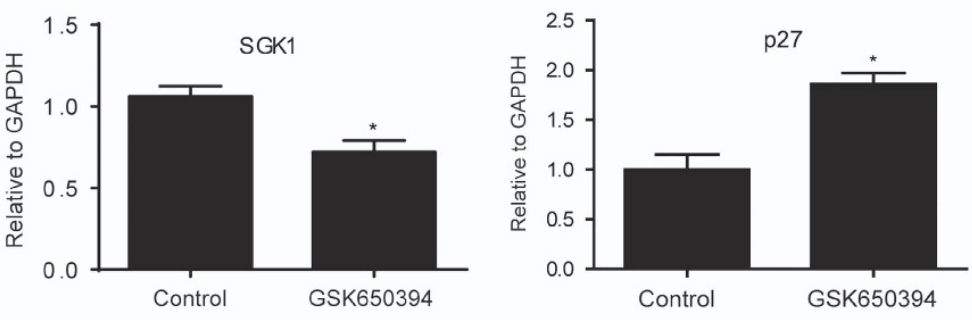

d

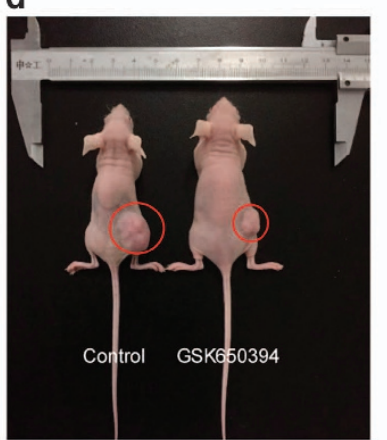

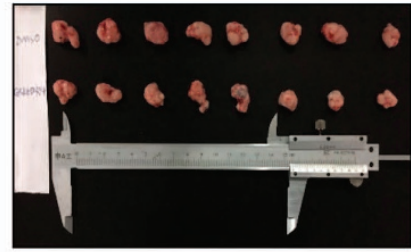

Control

GSK650394
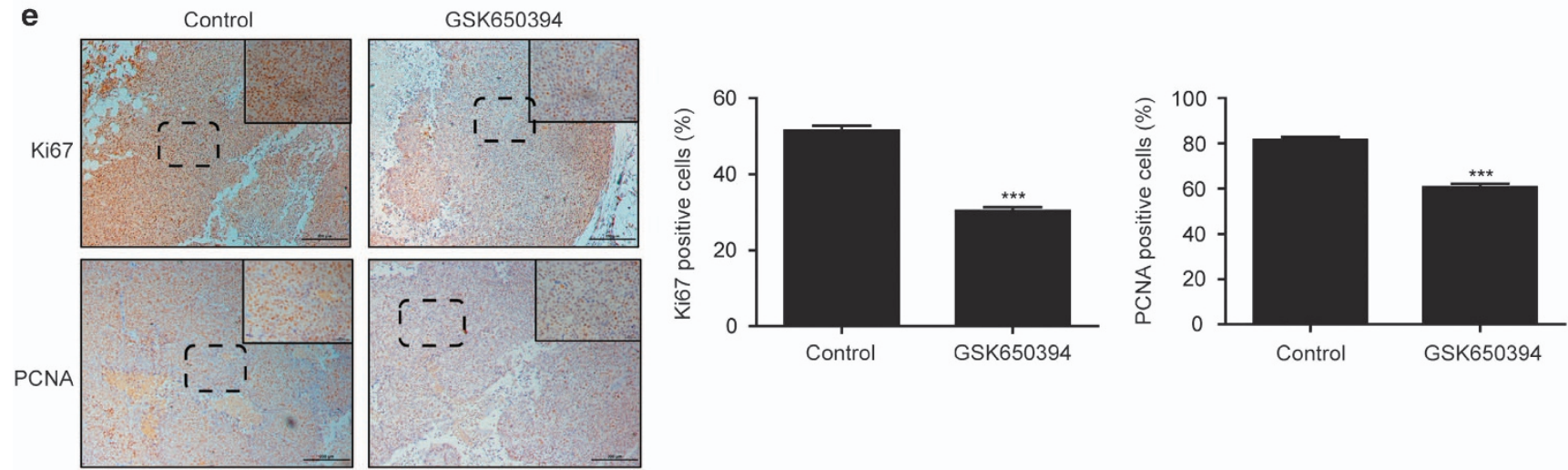

Figure 7 Therapeutic SGK1 inhibition upregulates p27 expression and represses tumor growth and cellular proliferation in the subcutaneous xenograft mice model. (a) The procedure of establishing a xenotransplant mouse model, followed by treatment with GSK650394; $n=8$. (b) p27 expression in xenograft tumor samples. (c, d) Transplanted tumor volume and size; $n=8$. (e) Ki67- and PCNA-positive cell populations in xenograft tumor tissues. Scale bars, $200 \mu \mathrm{m} ;{ }^{*} P<0.05 ; * * * P<0.001$.

Multiple signal pathways modulate p27 activity, and its downstream signals control the final decision of the cell cycle between progress and arrest. ${ }^{35}$ Alterations in p27 expression play vital roles in colorectal carcinogenesis through regulation of cyclin-dependent kinase subunit $1{ }^{36}$ SGK1 was shown to phosphorylate p27 and promote cytoplasmic p27 mislocalization in vitro. ${ }^{22}$ Here we demonstrated that overexpression of SGK1 reduced, while inhibition of SGK1 increased, p27 mRNA and protein levels in HCT116 cells, suggesting the transcriptional regulation of 27 by SGK1. MG132 alone could protect p27 from degradation in the cytoplasm of HCT116 cells; however, compared to controls, the cytoplasmic expression of p27 was unchanged, while the nuclear expression of p27 was significantly increased after combined treatment with GSK650394 and MG132. It has been reported that p27 nuclear localization is essential for G1/S arrest and the exclusion of p27 from the nucleus promotes G1/S cell cycle transition. Thus, our results indicated that SGK1 inhibitors repressed the G1/S-phase transition and reduced colorectal tumor cell proliferation by increasing the expression and nuclear accumulation of p27. 
However, whether SGK1 inhibitors promote p27 nuclear importation or inhibit p27 nuclear exportation requires further analysis.

Furthermore, functional rescue assays showed that p27 siRNAs significantly promoted cell proliferation and attenuated cell-cycle arrest induced by SGK1 inhibitors. However, p27 siRNAs failed to fully rescue the defects of colorectal cancer cell proliferation, migration and survival caused by SGK1 inhibitors. Thus, these results demonstrated that SGK1 promotes tumor growth and cell proliferation, at least in part, through targeting p27. Other downstream factors of SGK1 should be investigated in the future.

Collectively, our results demonstrate that SGK1 is overexpressed in tumor tissues from colorectal cancer patients and plays key roles in promoting cellular proliferation, migration and survival during CRC development. Importantly, our findings indicate that inhibition of SGK1 might be a promising therapeutic option for colorectal cancer.

\section{CONFLICT OF INTEREST}

The authors declare no conflicts of interest.

\section{ACKNOWLEDGEMENTS}

This work was supported by the grants from the National Natural Science Foundation of China (81470515 to JHX and 21672136 to BX), the Shanghai Medical Guide Project from the Shanghai Science and Technology Committee (134119a3000 to JHX) and the development fund for Shanghai talents (to JJX).

\section{PUBLISHER'S NOTE}

Springer Nature remains neutral with regard to jurisdictional claims in published maps and institutional affiliations.

1 Siegel RL, Miller KD, Jemal A. Cancer statistics, 2016. CA Cancer J Clin 2016; 66: 7-30.

2 Devetzi M, Kosmidou V, Vlassi M, Perysinakis I, Aggeli C, Choreftaki T et al. Death receptor 5 (DR5) and a 5-gene apoptotic biomarker panel with significant differential diagnostic potential in colorectal cancer. Sci Rep 2016; 6: 36532.

3 Douillard JY, Oliner KS, Siena S, Tabernero J, Burkes R, Barugel M et al. Panitumumab-FOLFOX4 treatment and RAS mutations in colorectal cancer. N Eng/ J Med 2013; 369: 1023-1034.

4 Van Cutsem E, Kohne CH, Hitre E, Zaluski J, Chang Chien CR, Makhson A et al. Cetuximab and chemotherapy as initial treatment for metastatic colorectal cancer. N Engl J Med 2009; 360: $1408-1417$

5 Zhai Z, Yu X, Yang B, Zhang Y, Zhang L, Li X et al. Colorectal cancer heterogeneity and targeted therapy: clinical implications, challenges and solutions for treatment resistance. Semin Cell Dev Biol 2016; 64: 107-115.

6 Webster MK, Goya L, Ge Y, Maiyar AC, Firestone GL. Characterization of sgk, a novel member of the serine/threonine protein kinase gene family which is transcriptionally induced by glucocorticoids and serum. Mol Cell Biol 1993; 13: 2031-2040.

7 Kobayashi T, Deak M, Morrice N, Cohen P. Characterization of the structure and regulation of two novel isoforms of serum- and glucocorticoid-induced protein kinase. Biochem J 1999; 344: 189-197.

8 Maiyar AC, Huang AJ, Phu PT, Cha HH, Firestone GL. p53 stimulates promoter activity of the sgk. serum/glucocorticoid-inducible serine/threonine protein kinase gene in rodent mammary epithelial cells. J Biol Chem 1996: 271: 12414-12422.
9 Mizuno $\mathrm{H}$, Nishida E. The ERK MAP kinase pathway mediates induction of SGK (serum- and glucocorticoid-inducible kinase) by growth factors. Genes Cells 2001; 6: 261-268.

10 You H, Jang Y, You-Ten Al, Okada H, Liepa J, Wakeham A et al. p53dependent inhibition of FKHRL1 in response to DNA damage through protein kinase SGK1. Proc Natl Acad Sci USA 2004; 101: 14057-14062.

11 Waldegger S, Barth P, Raber G, Lang F. Cloning and characterization of a putative human serine/threonine protein kinase transcriptionally modified during anisotonic and isotonic alterations of cell volume. Proc Natl Acad Sci USA 1997; 94: 4440-4445.

12 Leong ML, Maiyar AC, Kim B, O'Keeffe BA, Firestone GL. Expression of the serum- and glucocorticoid-inducible protein kinase, Sgk, is a cell survival response to multiple types of environmental stress stimuli in mammary epithelial cells. J Biol Chem 2003; 278: 5871-5882.

13 Hanahan D, Weinberg RA. The hallmarks of cancer. Cell 2000; 100: 57-70.

14 Bruhn MA, Pearson RB, Hannan RD, Sheppard KE. Second AKT: the rise of SGK in cancer signalling. Growth Factors 2010; 28: 394-408.

15 Sherk AB, Frigo DE, Schnackenberg CG, Bray JD, Laping NJ, Trizna W et al. Development of a small-molecule serum- and glucocorticoidregulated kinase- 1 antagonist and its evaluation as a prostate cancer therapeutic. Cancer Res 2008; 68: 7475-7483.

16 Amato R, Menniti M, Agosti V, Boito R, Costa N, Bond HM et al. IL-2 signals through Sgk1 and inhibits proliferation and apoptosis in kidney cancer cells. J Mol Med 2007; 85: 707-721.

17 Lang F, Bohmer C, Palmada M, Seebohm G, Strutz-Seebohm N, Vallon V. (Patho)physiological significance of the serum- and glucocorticoidinducible kinase isoforms. Physiol Rev 2006; 86: 1151-1178.

18 Lang F, Artunc F, Vallon V. The physiological impact of the serum and glucocorticoid-inducible kinase SGK1. Curr Opin Nephrol Hypertens 2009; 18: 439-448.

19 Wu W, Zou M, Brickley DR, Pew T, Conzen SD. Glucocorticoid receptor activation signals through forkhead transcription factor $3 a$ in breast cancer cells. Mol Endocrinol 2006; 20: 2304-2314.

20 Tangir J, Bonafe N, Gilmore-Hebert M, Henegariu O, Chambers SK. SGK1, a potential regulator of $\mathrm{c}$-fms related breast cancer aggressiveness. Clin Exp Metastasis 2004; 21: 477-483.

21 Zhang L, Cui R, Cheng X, Du J. Antiapoptotic effect of serum and glucocorticoid-inducible protein kinase is mediated by novel mechanism activating I\{kappa\}B kinase. Cancer Res 2005; 65: 457-464.

22 Hong F, Larrea MD, Doughty C, Kwiatkowski DJ, Squillace R, Slingerland JM. mTOR-raptor binds and activates SGK1 to regulate p27 phosphorylation. Mol Cell 2008; 30: 701-711.

23 Papadopoulou N, Charalampopoulos I, Anagnostopoulou V, Konstantinidis G, Foller M, Gravanis A et al. Membrane androgen receptor activation triggers down-regulation of $\mathrm{PI}-3 \mathrm{~K} / \mathrm{Akt} / \mathrm{NF}-\mathrm{kappaB}$ activity and induces apoptotic responses via Bad, FasL and caspase-3 in DU145 prostate cancer cells. Mol Cancer 2008; 7: 88.

24 Wang K, Gu S, Nasir O, Foller M, Ackermann TF, Klingel K et al. SGK1dependent intestinal tumor growth in APC-deficient mice. Cell Physiol Biochem 2010; 25: 271-278.

25 Towhid ST, Liu GL, Ackermann TF, Beier N, Scholz W, Fuchss T et al. Inhibition of colonic tumor growth by the selective SGK inhibitor EMD638683. Cell Physiol Biochem 2013; 32: 838-848.

26 Hengst L, Reed SI. Inhibitors of the Cip/Kip family. Curr Top Microbiol Immunol 1998; 227: 25-41.

27 Sherr CJ, Roberts JM. CDK inhibitors: positive and negative regulators of G1-phase progression. Genes Dev 1999; 13: 1501-1512.

28 Slingerland J, Pagano M. Regulation of the cdk inhibitor p27 and its deregulation in cancer. J Cell Physiol 2000; 183: 10-17.

29 Chu IM, Hengst L, Slingerland JM. The Cdk inhibitor p27 in human cancer: prognostic potential and relevance to anticancer therapy. Nat Rev Cancer 2008; 8: 253-267.

30 Chu I, Sun J, Arnaout A, Kahn H, Hanna W, Narod S et al. p27 phosphorylation by Src regulates inhibition of cyclin E-Cdk2. Cell 2007; 128: 281-294.

31 Prasad SB, Yadav SS, Das M, Modi A, Kumari S et al. PI3K/AKT pathway-mediated regulation of p27Kip1 is associated with cell cycle arrest and apoptosis in cervical cancer. Cell Oncol 2015; 38 215-225.

32 Firestone GL, Giampaolo JR, O'Keeffe BA. Stimulus-dependent regulation of serum and glucocorticoid inducible protein kinase (SGK) transcription, 
subcellular localization and enzymatic activity. Cell Physiol Biochem 2003; 13: $1-12$

33 Zhang BH, Tang ED, Zhu T, Greenberg ME, Vojtek AB, Guan KL. Serumand glucocorticoid-inducible kinase SGK phosphorylates and negatively regulates B-Raf. J Biol Chem 2001; 276: 31620-31626.

34 Sakoda $\mathrm{H}$, Gotoh $\mathrm{Y}$, Katagiri $\mathrm{H}$, Kurokawa $\mathrm{M}$, Ono $\mathrm{H}$, Onishi $\mathrm{Y}$ et al. Differing roles of Akt and serum- and glucocorticoid-regulated kinase in glucose metabolism, DNA synthesis, and oncogenic activity. J Biol Chem 2003; 278: 25802-25807.

35 Pagano M. Control of DNA synthesis and mitosis by the Skp2-p27Cdk1/2 axis. Mol Cell 2004; 14: 414-416.

36 Bochis OV, Irimie A, Pichler M, Berindan-Neagoe I. The role of Skp2 and its substrate CDKN1B (p27) in colorectal cancer. J Gastrointestin Liver Dis 2015; 24: 225-234. (c) (i)(-)(2) This work is licensed under a Creative Commons Attribution-NonCommercial-ShareAlike 4.0 International License. The images or other third party material in this article are included in the article's Creative Commons license, unless indicated otherwise in the credit line; if the material is not included under the Creative Commons license, users will need to obtain permission from the license holder to reproduce the material. To view a copy of this license, visit http:// creativecommons.org/licenses/by-nc-sa/4.0/

(C) The Author(s) 2017

Supplementary Information accompanies the paper on Experimental \& Molecular Medicine website (http://www.nature.com/emm) 